\title{
The Rise of Artificial Intelligence under the Lens of Sustainability
}

\author{
Jayden Khakurel ${ }^{1, *(\mathbb{D})}$, Birgit Penzenstadler ${ }^{2, *} \mathbb{C}$, Jari Porras ${ }^{1}$, Antti Knutas ${ }^{1}(\mathbb{C}$ and \\ Wenlu Zhang ${ }^{2}$ \\ 1 School of Engineering Science, Lappeenranta University of Technology, 53850 Lappeenranta, Finland; \\ jari.porras@lut.fi (J.P.); Antti.knutas@lut.fi (A.K.) \\ 2 Computer Engineering and Computer Science, California State University, Long Beach, CA, 90840, USA; \\ Wenlu.Zhang@csulb.edu \\ * Correspondence: jayden.khakurel@lut.fi (J.K); birgit.penzenstadler@csulb.edu (B.P.)
}

Received: 21 October 2018; Accepted: 1 November 2018; Published: 3 November 2018

\begin{abstract}
Since the 1950s, artificial intelligence (AI) has been a recurring topic in research. However, this field has only recently gained significant momentum because of the advances in technology and algorithms, along with new AI techniques such as machine learning methods for structured data, modern deep learning, and natural language processing for unstructured data. Although companies are eager to join the fray of this new AI trend and take advantage of its potential benefits, it is unclear what implications AI will have on society now and in the long term. Using the five dimensions of sustainability to structure the analysis, we explore the impacts of AI on several domains. We find that there is a significant impact on all five dimensions, with positive and negative impacts, and that value, collaboration, sharing responsibilities; ethics will play a vital role in any future sustainable development of $\mathrm{AI}$ in society. Our exploration provides a foundation for in-depth discussions and future research collaborations.
\end{abstract}

Keywords: sustainability; artificial intelligence; machine learning; ethics; social impacts

\section{Introduction}

The progress and opportunities of artificial intelligence (AI) have been discussed by both technology enthusiasts (those who believe technology creates opportunities and eliminates inequalities) and technophobes (those who are disproportionately afraid of technology) [1].

A controversial subject, AI has been discussed ever since its inception in the 1950s by John McCarthy [2]. However, even earlier, the possibilities of "machine intelligence" or "artificial intelligence" were already recognized and discussed in the mid-1940s by Turing [3]. Technology enthusiast, physicist, and AI researcher Max Tegmark talks about the opportunities of AI and is convinced we can grow the world's prosperity through automation, without leaving people lacking income or purpose; according to Tegmark, when AI is utilized in this manner, humanity does not have to fear an arms race [4]. Yuval Harari argues against this by pointing out that "instead of fearing assassin robots that try to terminate us, we should be concerned about hordes of bots who know how to press our emotional buttons better than our mother" [5]. One current example that has received a lot of attention is the debate surrounding the last U.S. election and how voters were influenced by [6]. The ability to scrape data from across multiple social media platforms and capture user behavior patterns and comments combined with a mix of machine learning, statistics, robust programming skills, and both artificial and natural intelligence enables one to capture and influence human behavior [7]. 
Rather than worry about an unlikely existential threat, Grady Booch urges the consideration of how AI will enhance human life [8]. In line with this, digital visionary Kevin Kelly argues that AI can bring on a second Industrial Revolution [9].

In contrast, neuroscientist Sam Harris states that although scientists are going to build superhuman machines, we have not yet grappled with the problems associated with creating something that may treat people the way we treat ants [10]. More specifically, techno-sociologist Zeynep Tufekci explains how intelligent machines can fail in ways that are different from human error patterns, ways we do not expect or are prepared for and that call for holding on ever tighter to human values and ethics [11].

According to Tegman, the "elephant in the room" that we should be discussing is where we want to go with AI, that is, which society we are aiming toward, rather than focusing on how to make AI more powerful and steer it better [12]. Fisher [13] states in the context of AI that, "Sustainability is a vast concern, or should be, and presents challenges stemming from interactions between the natural and human-developed spheres across temporal and spatial scales" [13] (p. 4852). Fisher further notes this as a motivation for computer science researchers to apply their knowledge of working on environmental and societal sustainability challenges to AI. He concludes that computational sustainability has taken hold as a vibrant area of use-driven basic research for AI.

We take this as an opportunity to explore the relation between AI and sustainability, as well as sustainable development, in terms of a technology impact assessment. This leads to the following central question for our research, which we base on previous work in sustainability assessment [14].

Research question: What are the potential long-term impacts of AI on sustainability and, more specifically, on sustainable development?

Research design: We use a simplified version of the template for a sustainability analysis by Becker et al. [14] to explore the potential positive and negative influences of AI on the dimensions of sustainability. The first two authors of this paper elaborated the first version on the basis of previous work and literature study based on snowballing from our results to keywords for AI and the individual sustainability dimensions. We then iterated the analysis in discussion amongst all authors. Subsequently, we performed a focus group with a set of experts, the Karlskrona Consortium.

Outline: Section 2 describes the background of artificial intelligence, the sustainability analysis, and what sustainable development is. Section 3 presents the sustainability analysis of the domains of $\mathrm{AI}$, Section 4 opens an in-depth discussion of the issues caused by AI, and Section 5 summarizes the next steps in AI sustainability and other areas of research.

\section{Background}

In this section, we introduce the background for the work at hand in three categories: Artificial intelligence, sustainability analysis, and sustainable development.

\subsection{Artificial Intelligence}

This subsection details the history and types of AI and its implications as discussed over the years. AI can be described as a cluster of technologies [15] and approaches, that is, statistical and symbolic [16] that aim at mimicking human cognitive functions [17] or exhibiting aspects of human intelligence by performing various tasks, mostly preceding analytical, analytical mostly preceding intuitive and intuitive mostly preceding empathetic intelligence [18].

AI has been a constant theme in computing research and many researchers, including Turing, have conducted research on AI. For example, McCarthy proposed a research project in the 1950s to find out how to make machine language, form abstractions and concepts, solve different kinds of problems then only reserved for humans, and, with the resulting technology, improve humans themselves [2]. Similarly, in 1966, Joseph Weizenbaum [19] demonstrated the Eliza chatbot, a natural man-machine communication system. With over 60 years of research, much progress has been made in AI, and especially, different types of AI are accelerating together with their related technologies. Not 
to mention, the invention of intelligent machines have further accelerated the development of AI [20]. For example, Strelkova et al. [21] identified three levels of artificial intelligence, as follows:

1. Artificial narrow intelligence (ANI): Machines are trained for a particular task and can make a decision only in one sphere. (e.g., Google search, passenger planes [21])

2. Artificial general intelligence (AGI): AGI which are also known as strong AI," "human-level $\mathrm{AI}$," and "true synthetic intelligence [22] are machines that has ability to reach and then pass the intelligence level of a human, meaning it has the ability to reason, plan, solve problems, think abstractly, comprehend complex ideas, learn quickly, and learn from experience. (e.g., autonomous cars)

3. Artificial super intelligence (ASI): An intellect that is much smarter than the best human brain in every field, including scientific creativity, general wisdom, and social skills. (e.g., robots that can adapt like animals [23], game designed by Google "Alphago" [24])

Similarly, Huang et al. [18] discussed four types of intelligences. The four types of intelligences are as follows:

1. Mechanics: Minimal degree of learning or adaption (e.g., McDonald's "Create Your Taste" touchscreen kiosks)

2. Analytical: Learns and adapts systematically based on data (e.g., Toyota's in-car intelligent systems replacing problem diagnostic tasks for technicians)

3. Intuitive: Learns and adapts intuitively based on understanding (e.g., Associated Press' robot reporters taking on the reporting task for minor league baseball games)

4. Empathetic: Learn and adapt empathetically based on experience (e.g., Chatbots communicating with customers and learning from these experiences)

Both the levels and intelligences feature many activities that may include creativity, the ability to understand spoken language, rational inference, and making judgments based on insufficient and conflicting data as well as previous experiences. However, such activities may have both benefits and disadvantages in today's society, with previous research raising such issues. For example, Stephen Hawking [25] indicates that while AI is vastly helpful for reducing disease, poverty, and reinstating natural surroundings, it is difficult to foretell what we may attain when AI augments our minds. He further warns that engineers should understand the ethics behind AI before it destroys humans. Carriço [26] analyses the potential benefits and drawbacks of AI. Carriço states the biggest threat from $\mathrm{AI}$ is the potential of its weaponization, but it may also transform jobs, undo the damage humans have done to the planet through industrialization, open the road to ending poverty, and help eradicate disease. Similarly, Popenici et al. [27] explores the emergence of AI use and its impact in teaching and learning in higher education. The study asserts that having AI in education may bring biases through complex algorithms designed by programmers who transmit their own biases or agendas through operating systems. Popenici et al. [27] further states, "Now is the time for universities to rethink their function and pedagogical models and their future relation with AI solutions and their owners" (p. 13). Pavaloiu et al. [28] also suggests that outsourcing ethics is impossible in AI, even though there is algorithmic responsibility since every other system, however refined, cannot always perform the right things in the correct manner and for the proper reasons. Systems such as robots are unreliable and cannot be fully trusted due to their unreliability. Fear exists in our minds of these robots doing the right thing, becoming autonomous, and rebelling against humans one day. Ethical laws, then, must be considered when designing and deploying robots.

\subsection{Sustainability Analysis}

The sustainability analysis investigates what sustainability means for the system under development and how the sustainability of the application's domain context will be impacted by the system [29]. To structure this analysis, two concepts are used: sustainability dimensions and orders 
of impact. The sustainability dimensions are individual, social, economic, technical, and environmental. We refer to the definition of sustainability dimensions found in [14] as follows:

- The individual dimension covers individual freedom and agency (the ability to act in an environment), human dignity, and fulfillment. It includes individuals' ability to thrive, exercise their rights, and develop freely.

- The social dimension covers relationships between individuals and groups. For example, it covers the structures of mutual trust and communication in a social system and the balance between conflicting interests.

- The economic dimension covers financial aspects and business value. It includes capital growth and liquidity, investment questions, and financial operations.

- The technical dimension covers the ability to maintain and evolve artificial systems (such as software) over time. It refers to maintenance and evolution, resilience, and the ease of system transitions.

- The environmental dimension covers the use and stewardship of natural resources. It includes questions ranging from immediate waste production and energy consumption to the balance of local ecosystems and climate change concerns.

Although the original template also uses first-(direct), second-(indirect), and third-(structural) order impacts, we abstract from those for the sake of simplicity because the focus is on second-order impacts- the ones induced by using AI systems. There may be several questions asked about the relation between AI and sustainability, for example, the sustainability of AI (how AI evolves) or the impact of AI on society (in terms of generations and needs). In the current article, we focus on the second one-the impact on society; hence, we additionally introduce the concept of sustainable development.

In other works, we also analyzed the sustainability impacts according to several time horizons, according to the LES model of Life-cycle effects, Enabling effects, and Structural effects [30]. As in the work at hand the additional complexity of the time scales would have required us to narrow down the scoping of the system to an individual one as opposed to an overview of application domains for AI, we opted to abstract from the different orders of effect.

We use a checklist of questions to get the discussion started in each of the five dimensions across the three orders of impact and involve a diverse set of stakeholders [31] to get to an encompassing picture.

We have previously used the sustainability analysis in an industry evaluation [32] as well as in teaching $[14,29]$ and expanded its opportunities for use further in the contribution at hand. In their work, Becker et al. [14] introduce the sustainability analysis as a tool that helps visualize the widespread potential effects across the sustainability dimensions and orders of impact for a specific software-intensive system under analysis. In another work, Penzenstadler [29] reports on the use of the sustainability analysis as one of the artifacts in a course for Master students and PhD students on software engineering for sustainability. In a previous paper [32], we first trained a consultant in performing and guiding through a sustainability analysis during requirements elicitation and negotiation, and then observed a workshop where the consultant moderated and performed the analysis with their customers.

In contrast, the work at hand uses the sustainability analysis for a larger scope and as a research tool for exploring the potential sustainability effects of a technology on the rise.

\subsection{Sustainable Development}

Beyond the general notion of the concept of sustainability, the United Nations (UN) specifically contributed to the idea of sustainable development. In fact, the UN authored one of the most-cited definitions of it: "Development that meets the needs of the present without compromising on the ability for future generations to meet their needs" [33]. In 2000, the UN set out and defined the 
Millennium Declaration's goal of halving extreme poverty, which is defined by having less than $\$ 1.25$ per day, by 2015 [34]. All 191 United Nations member states at the time, and at least 22 international organizations, committed to help achieve the following Millennium Development Goals by 2015. The eight goals were as follows:

1. To eradicate extreme poverty and hunger

2. To achieve universal primary education

3. To promote gender equality and empower women

4. To reduce child mortality

5. To improve maternal health

6. To combat HIV / AIDS, malaria, and other diseases

7. To ensure environmental sustainability

8. To develop a global partnership for development

By 2015, the metrics had not been completely reached, but considerable progress had been made [35]. For example, when it came to the first goal, in 1990, nearly half of the population in the developing world lived on less than $\$ 1.25$ a day; that proportion dropped by $14 \%$ in 2015. Globally, the number of people living in extreme poverty has declined by more than half, falling from 1.9 billion in 1990 to 836 million in 2015. Most of this progress has occurred since 2000. The number of working middle class in developing nations, who are living on more than $\$ 4$ a day, has almost tripled between 1991 and 2015. This group now makes up half the workforce in developing regions, up from just $18 \%$ in 1991. The proportion of undernourished people in developing regions has fallen by almost half since 1990, from $23.3 \%$ in 1990-1992 to 12.9\% in 2014-2016. Similar indicators of significant progress were reported for the other goals. As a follow-up, in 2015, the UN's Sustainable Development Goals were redefined to further eradicate poverty [36]. Currently, the UN's 2030 Agenda is a plan of action intended for people, planet, and prosperity that seeks to strengthen universal peace and secure the freedom of people around the world. The signatories of this resolution recognize that eradicating poverty in all its forms and dimensions, including extreme poverty, is the greatest global challenge and an indispensable requirement for sustainable development. The Sustainable Development Goals stated in the 2030 Agenda are as follows:

1. End poverty in all its forms, everywhere

2. End hunger, achieve food security and improved nutrition, and promote sustainable agriculture

3. Ensure healthy lives and promote well-being for all people at all ages

4. Ensure inclusive and equitable quality education and promote lifelong learning opportunities for all

5. Achieve gender equality and empower all women and girls

6. Ensure the availability and sustainable management of water and sanitation for all

7. Ensure access to affordable, reliable, sustainable, and modern energy for all

8. Promote sustained, inclusive, and sustainable economic growth, full and productive employment, and decent work for all

9. Build a resilient infrastructure, promote inclusive and sustainable industrialization, and foster innovation

10. Reduce inequality within and among countries

11. Make cities and human settlements inclusive, safe, resilient, and sustainable

12. Ensure sustainable consumption and production patterns

13. Take urgent action to combat climate change and its impacts*

14. Conserve and sustainably use the oceans, seas, and marine resources for sustainable development

15. Protect, restore, and promote the sustainable use of terrestrial ecosystems, sustainably manage forests, combat desertification, and halt and reverse land degradation and biodiversity loss 
16. Promote peaceful and inclusive societies for sustainable development, provide access to justice for all, and build effective, accountable, and inclusive institutions at all levels

17. Strengthen the means of implementation and revitalize the global partnership for sustainable development

The 2018 status report on the 2030 agenda [37] highlights that there is progress being made in a lot of areas of the 2030 Agenda. For example, the maternal mortality ratio in sub-Saharan Africa has declined by $35 \%$ and the under-five mortality rate has dropped by $50 \%$ since 2000 . In South Asia, a girl's risk of being married off while still a child has declined by over $40 \%$. Furthermore, the proportion of people with access to electricity has more than doubled in the least-developed countries. Globally, labor productivity has increased, and unemployment rates have decreased. More than 100 countries have sustainable consumption and production policies and initiatives. However, in some areas, progress is not sufficient for meeting these goals by 2030, specifically for the most disadvantaged and marginalized groups. Many of these goals can be worked towards with the help of socio-technical systems for sustainability, which, in turn, can benefit immensely from using AI. However, AI brings not only opportunities but also risks for negative impacts for sustainability, as detailed in the following section.

\section{AI under a Sustainability Analysis Perspective}

This section presents and explains a sustainability analysis of the AI field using the lens of the five dimensions presented in the sustainability analysis section. Figure 1 shows the sustainability analysis diagram of the AI field according to the five dimensions of sustainability.

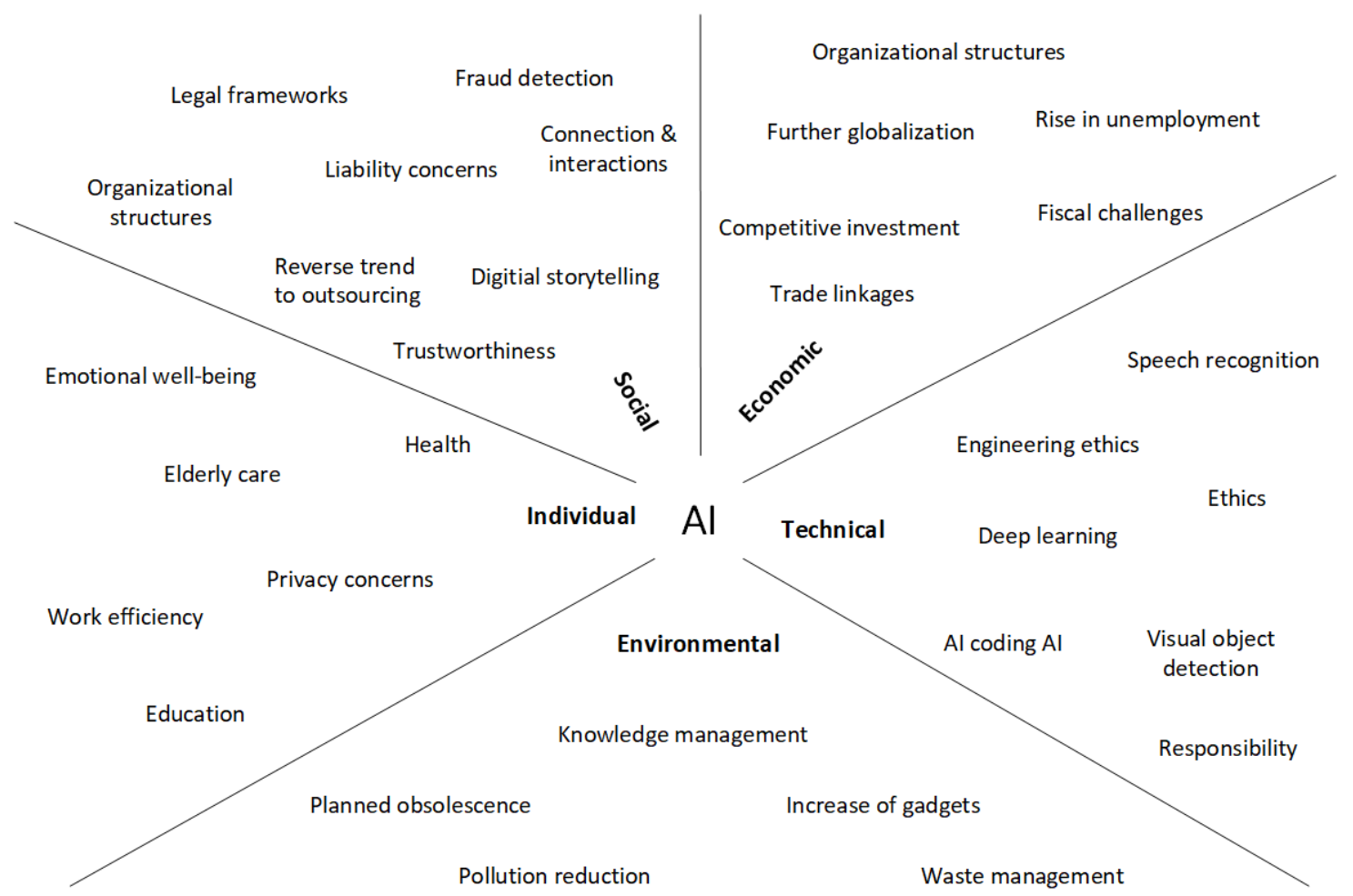

Figure 1. Sustainability analysis diagram of the artificial intelligence (AI) field according to the five dimensions of sustainability.

\subsection{Economic Dimension}

Gartner predicts that by 2022, $40 \%$ of customer-facing employees and government workers will consult an AI-powered virtual agent every day for decision-making or process-related support [38]. 
In addition, governments of countries with advanced economies and large technology companies are investing in the implementation of AI to create a competitive advantage. For example, the government of the United Kingdom (UK) recently announced a $£ 1$ billion deal to put the nation at the forefront of the AI industry [39]. Similarly, France has planned to invest $€ 1.5$ billion into AI research [40]. First, such investments give a competitive advantage at the national level for advanced economies; however, they also have negative impacts on the globalization of production and services. Meaning, in the current scenario, companies from advanced economies outsource services, for example call centers and manufacturing, to emerging nations due to cost advantages. However, companies that maximize AI's capabilities will no longer have to worry about paying outsourcing costs and living wages. In addition, overhead costs will reduce or stop the outsourcing of services and production in the emerging market and bring services in-house. This shift may result in the reduction of products' prices and other expenditures of the companies. However, the question then arises: will the firm lower their product prices since production is automated?

Additionally, if companies from advanced economies bring their development back in-house, there may be disruptions in local businesses and the job markets of emerging economies, resulting in a rise in unemployment and a decrease in individuals' spending power. As Papadopoulos et al. [41] point out, "Trade linkages play a significant role in the spillover of crisis." This will eventually affect the global economy.

Furthermore, critics argue that the implementation of AI in automated in-house production services may also dislocate and pressure the wages of low-skilled workers and is starting to impinge on the employment prospects of middle-skilled workers, with only the most responsible creative, or supervisory roles remaining [42]. To adapt to these changes, low-skilled or middle-skilled, including older, workers must participate in training programs to give themselves new skills to reduce the risks of unemployment [43]. The question emerges, then, how much can the older population learn if they lack computational skills? If they cannot train themselves or adapt to changes, they will experience job loss eventually, or early retirements. The increase in early retirements will result in the need for reforms to pension and other social security programs, which will make it very difficult for many governments to maintain the solvency of many national pension systems or their overall fiscal balance [44].

\subsection{Technical Dimension}

According to Lecun et al. [45] "deep learning allows models that are composed of multiple processing layers to learn representations of data that have multiple levels of abstraction" (p. 436). These methods have significantly improved speech recognition, visual object detection and recognition, and other areas [45]. Deep learning models are a class of machines that can learn a hierarchy of features by building high-level features from low-levels ones. For example, the convolutional neural networks (CNNs) are a type of deep model that have been improving the machine learning and vision fields [46]. Object recognition can be used in many application domains and support visually disabled people, increase security systems, but also improve some warfare systems-the technology itself is agnostic of the purpose. Beyond the purpose of a system, the algorithms still have the challenge of misclassifying objects, and the question is what the controlling instance for checking object classification in each system is. There is an initial training dataset and then a training phase and the system can continue to learn but it is the decision of each developer as to how long the system needs to be trained until it is considered trustworthy or good enough to be suitable for purpose.

Even more recently, deep reinforcement learning is helping to teach sophisticated behaviors automatically, which can be further improved using recurrent neural networks [47]. All of these developments will lead to progress in AI being able to code AI [48].

The impact of this development is hard to foresee, except that it will increase the speed of research and development. In terms of the positive impact it may have, we can expect more capable systems that can take over more complex tasks. In terms of the negative impacts, we can perceive the necessity of stronger engineering ethics as more and more responsibilities are placed into the hands of the 
developers who engineer the systems upfront and hence must foresee many wanted and unwanted usage scenarios. This is a much greater, prematurely accumulated, responsibility than a machine operator would perceive when handling a machine every day and making individual, situation-specific decisions based on the operator's expertise and years of experience in the field. One initiative to deal with these developments is to revamp existing codes of ethics, for example, like what is currently being done with the ACM Code of Ethics [49], which has led to a broad discussion on where responsibility ends and social activism starts.

\subsection{Environmental Dimension}

AI may be useful in helping us take better care of the planet in terms of supporting waste and/or pollution management, but also, predictive systems can be used for earthquakes and weather forecasting to better recognize the likelihood of extreme event occurrences such as hurricanes and tsunamis. For example, Al-Jarrah et al. [50] reports on the impacts of improved waste management by using fuzzy inference models for site selection.

AI can also be used for better pollution management; for example, Ramachandran et al. proposed a modified Environmental Vulnerability Index (EVI) to assess the environmental impact of aviation on connected cities [51].

Furthermore, we can imagine knowledge-management systems integrated with deep-learning technology that could help analyze the images of animals captured by motion-sensor cameras in the wild. Such analyzed information could provide accurate, detailed, and up-to-date information about the location, count, and behavior of animals in the wild, which could be useful in enhancing local biodiversity [52] and local conservation efforts.

Also, the adoption of autonomous vehicles could be a possible turning point for reducing greenhouse gas emissions. For example, in the study, Igliński et al. [53] point to the potential of autonomous vehicles to reduce greenhouse gas emissions through less fuel consumption. This could be done as follows:

1. Programmed autonomous vehicles could fully take advantage of the principles of eco-driving throughout a journey, reducing fuel consumption by as much as 20 percent and reducing greenhouse gas emissions to a similar extent.

2. Autonomous vehicles could reduce traffic congestion by recommending alternative routes and shortest routes possible in urbanized areas and by sharing traffic information to other vehicles on the motorways, resulting in less fuel consumption.

3. Autonomous vehicles could drive in accordance with imposed limits, resulting in smooth driving that would minimalize the necessity of the energy-intensive process of accelerating. This would ensure that the least amount of fuel is used.

4. Finally, autonomous vehicles would reduce the distance between cars, would reduce fuel consumption due to reduction of aerodynamic resistance, and would reduce greenhouse gas emissions.

In addition to the positive impact, AI can also have negative impact towards environmental dimension especially due to the contribution it makes towards further acceleration, and consumption of technological devices. The increase production and consumption of technological devices will have two adverse effects, namely planned obsolescence and depletion of natural resources:

(i) Planned obsolescence resulting in the generation of electronic waste: The acceleration of technology is closely interlinked with planned obsolescence, which means to design products that wear out "prematurely" (i.e., have useful lives that were well below customer expectations); planned obsolescence has already been deemed unethical in 1960 [54]. There are physical obsolescence mechanisms, namely limited functional life design ("death dating"), design for limited repair, and design aesthetics, that lead to reduced satisfaction, and then there is technological obsolescence resulting in the generation of e-waste [55], namely the design for fashion and design for functional 
enhancement by adding or upgrading product features [56]. Sources indicate that in North America, over 100 million cell phones and 300 million personal computers are discarded each year due to acceleration of technology [56]. The initiatives that can shift this paradigm are public policy, environmental ethics, and corporate responsibility. The World Business Council on Sustainable Development includes the following as a major action point: "Encourage consumers to prefer eco-efficient, more sustainable products and services." [57]. However, Guiltinan identifies "two impediments: (1) the competitive pressure for and consumer expectations of frequent upgrades for durable goods and (2) the lack of consumer concern for environmental consequences when contemplating the upgrades of durable goods" [56] (p. 26).

(ii) Use of natural resources: Planned obsolescence in general is a problem that depletes the natural environment of resources such as rare earths while increasing the amount of waste to deal with. However, the rise of AI could potentially amplify these negative impacts, for example by further automating extraction in more complex environments that are dangerous to human operators. If a "mining robot" can take over the mining tasks in an AI-supported way, this may be able to further increase the yield of rare earths and increase the depletion rate. Thus, increase in depletion rate of natural resources will have environment degradation (i.e., is the deterioration of the environment through depletion of resources) as well as devastating consequences on both human health [58,59].

\subsection{Individual Dimension}

Becoming more efficient is not humanity's problem anymore. We have become increasingly more productive in the last 50 years [60]. However, due to job requirements and inflation, individuals are working more than before both in the United States as well as in other parts of the world [61]. A study of Song et al. [62] has shown that a person working more than normal working hours has a significantly higher risk of poor self-rated health and that this affects mental and emotional well-being. For example, it can lead to rising numbers of depression, burnout, anxiety, sleep disturbances, and chronic heart disease [60,63]. Previous research [64] has claimed "time" as a major constraint for individuals to participate in physical activities. As outlined in science fiction movies, the advancement of research in computing devices has led to the development of algorithms for "AI slaves" that are capable of performing intuitive and empathetic tasks at varying levels and in many different ways [18]. These algorithms are likely to benefit individuals and companies in eventually solving tasks that could significantly reduce working hours. In other words, AI-powered digital assistants, chatbots, analytical tools, and robots could help individuals in terms of working less hours, increase work efficiency, improve workers' physical well-being and reduce work-related injuries [65]. We have access to more information in less time, we can get better-tailored services, and we can perform more efficiently. For example, personal digital assistants, such as Amazon's Alexa or Apple's Siri, which are easily available, are likely to make some of our daily activities easier, more convenient, or more efficient via sophisticated voice interfaces that can perform tasks like searching and making calls. Furthermore, AI support systems in domains such as healthcare, elderly care, space exploration and transport [66] are expected to reduce employees' workloads. Out of many examples, a humanoid robot (i.e., "upright multi-functioning social robot that typically has facial features, usually quite schematic or cartoon-like features, some sort of communicative interface, and perhaps arms") at an elderly care center could provide recreational pastimes, help lift and carry household objects, keep track of the user's whereabouts in the house, register falls or other signs of harmful incidents, and understand the user's daily routine $[67,68]$. Although there are benefits, there are also major implications due to the robonomics (i.e., robot-based economy) within the individual dimension of sustainability [69]. Such implications are geared toward (i) an increase in anxiety-related mental health issues because of the fear of unemployment and sources of incomes [1,69]; and (ii) a change in individual behavior and interaction, that is, instead of having direct interaction with other people either at the store, via mobile phones, the individual will have more interaction with machines. This will subsequently reduce the 
meaningfulness of the human-to-human interactions that we have with others, disconnecting us from the world around us, creating more isolation and limiting us with digital emotions.

Researchers [70] have linked social isolation with increased mortality, incidence of heart disease, and functional decline. As Villani [71] stated, "Data is the raw material of AI and the emergence of new uses and applications depends on it." Therefore, for individuals, living in the AI era means giving all data to a vast design space, presumably much larger than that of the human mind [72]. Since, AI systems are artefacts, constructed by people to fulfill their own goals [73], motives, interests, and personal characteristics [74] and to make the machines more intelligent for some form of prediction using various input methods, such as cameras, text, gestures, and audio and analysis of deep-learning neural-networks techniques, a company could collect the data without an individual's knowledge or consent. For example, Google could collect a user's location data even when the setting is turned off, or Google's digital assistant "Home Mini" could listen to a user's conversations due to a "phantom" issue. This raises questions on how much privacy individuals really have in the era of AI when data are collected intentionally or unknowingly (i.e., issues caused by the machines)? Furthermore, the rise of AI requires changes in education, which is also part of individual sustainability. In terms of education, changes in the workplace will require mathematics, information technology, science and technology, but also design thinking methods, as the next generation of employees must learn to adapt quickly to the technical, social and digital change, because it is to be expected that even a " 5 th industrial revolution will not be long in coming" [75].

\subsection{Social Dimension}

For the social dimension, we can see benefits, as well as the dangers; there is the chance to strengthen communities, but also a requirement to develop legal frameworks around AI, and all of the strengths and weaknesses here come with the threat of turning over too much power to AI.

AI systems could help strengthen communities by helping with various small roles of supporting the development of networks, conducting the administration and facilitation of collaboration, and taking over simple tasks in households, nursing, and teaching [75]. There are differing opinions here on whether AI could do these tasks. The question is poignant. To do these tasks, AI will have to be able to learn like humans because these skills require a certain extent of socio-cultural materiality ("wanting to have things") on the side of the AI. For example, Hasse [76] argues that machines "do not learn like humans because they do not learn how to constantly make a volatile world meaningful, instead running on fixed abstract, yet material algorithms that are not about thinking, but about symbolic representation" [76] (p. 10). On the other hand, AI may well be able to assist in a task such as classroom teaching [77], yet several ethical issues need to be examined for this, such as the privacy of children's data, the responsibility boundaries between teachers and robots, and the potential for the AI's negative influence. However, influence from AI could also be positive, as explored in [78], who discusses robots and the ethical appropriateness of nurturing empathy and charitable behavior; the author is particularly interested in whether a companion robot could encourage humans to perform charitable acts and whether it is ethical to follow such a design path. Another area where social interactions are being automated is for social media and online community management. As the number of users in online services increases, the manual management of users becomes increasingly challenging. Currently, different content management techniques, such as the detection of trends [79] or artificially created social campaigns [80] are used.

Copeland and de Moor [81] explore how shared stories can support community groups in identifying what they seek to change, and they propose an approach of how digital storytelling can be effectively implemented in community partnership projects focused on physical spaces. They find four dimensions of trust are imperative for successful storytelling: (1) legitimacy-selected storytellers truly represent the stakeholders they tell stories about, (2) authenticity-authentic voices are needed to affect change, (3) synergy—weaving together multiple legitimate and authentic voices, 
and (4) commons-any collectively owned resource. If AI systems are to be successful in supporting communities, they need to evoke trustworthiness, and digital storytelling might help in that.

Part of this trustworthiness can be provided through legal frameworks. Kingston [82] discusses whether criminal liability could ever apply in the context of AI; to whom it might apply; and, under civil law, whether an AI program is a product that is subject to product design legislation or a service to which the tort of negligence applies. He concludes that the question of whether AI systems can be held legally liable depends on at least three factors: the limitations of AI systems and whether these are known and communicated to the purchaser; whether an AI system is a product or a service; and whether the offence requires mens rea or is a strict liability offence. Although this may be a future scenario, it has already occurred in 1981 when a person was accidentally killed by an AI system. Hallvey begins her article on the criminal liability of AI [83] with the following report: "In 1981, a 37-year-old Japanese employee of a motorcycle factory was killed by an artificial-intelligence robot working near him. The robot erroneously identified the employee as a threat to its mission and calculated that the most efficient way to eliminate this threat was by pushing him into an adjacent operating machine" [83] (p. 1). She concludes that because AI entities are taking part in human activities and because offenses have already been committed by AI entities or through them, there is no substantive legal difference between the idea of criminal liability imposed on corporations and on AI entities. Consequently, precedence models of criminal liability do exist, along with the general paths to impose a punishment. This would also have to include regulations to avoid AI warfare, where a mistaken interpretation of a real-world event by an AI system could lead to serious conflicts.

In the workplace, AI could reverse the trend of outsourcing; for example, call centers that have been outsourced for the past decade can be replaced by AI systems. Many routine activities involving operating software can be automated, for example, in Human Resources (HR) [84], call centers [85], or even bypassing human customer service through user-bot interactions [86].

\section{Discussion}

In this paper, we see the different effects that AI can have as factors that can intensify development either way, towards more or less globalization, towards more or less equality, and towards more or less justice and peace. As pointed out by Ehrenfeld [87], many of our current sustainability interventions via IT are measures to reduce unsustainability instead of creating sustainability, which means that we have to significantly shift our thinking towards a transformation mindset for a joint sustainable vision of the future. In this section, we discuss how we could reduce such negative impact that was discovered during analysis before AI becomes more widespread across multiple application domains, which, in turn, may also affect the UN's Sustainable Development Goals [36].

Different categories of values—such as individual or personal values, object values, environmental values, professional or work values, national values, group values, and societal values [88]—are underlined within individual and organizational behaviors. These values are "determinants of virtually all kinds of behavior that could be called social behavior or social action, attitudes and ideology, evaluations, moral judgments and justifications of self to others, and attempts to influence others" [89] (p. 5). AI-enabled applications are dependent on how humans train them, while training value conflicts may arise because of the involvement of different stakeholders. Such conflicts of values may negatively impact society instead of proving to be beneficial. Therefore, in order for the society to benefit from AI, one way of reducing these negative impacts within the sustainability dimension is through aligning the values of all stakeholders during the design process of AI-enabled applications so that their goals and behaviors resemble the human values. For example, the AI-based applications designed to support law enforcement require datasets derived from the law, imposed by the national values of the government. In such scenarios, the designers or trainers should not mix their own self-oriented (or egocentric) values and other-oriented (or disinterested) values [90] with the national values, but should solely train the AI to align with the national values. With such alignment provided, AI systems could be less of a possible threat to humanity and strictly remain machines for solving tasks assigned to them. 
However, the framework for characterizing and organizing value systems that could help in aligning the values of each stakeholder is still missing.

On the other hand, we live in a world of limited resources, including time, energy, money and the great transitions [91]. In this context, nations, organizations compete to design AI enabled system to gain power and to have influence over others [92]. Having such desire in power, could help one nation to the achieve their long-term sustainability goals, however other to lose the three "pillars," i.e., economic development, environmental protection and social progress/equity [91]. Therefore, for society to benefit from AI, it is essential for all the stakeholders' technological designers, application developers, researchers and users (business and consumers), and government to collaborate and share the responsibilities rather than having influence over others. There are a different ways stakeholders could share the limited resources and great transitions in to actions. First could be with an "open, inclusive, and continuing global dialogue about what 'the good life' should look like, how to live it, and the values, attitudes and behaviors, both individual and collective, that will support it" [91] (p. 41).

Second with a proposal to update current strategies and policies on the organizational, national and global levels could improve the effect of $\mathrm{AI}$ in the five dimensions of sustainability. In such case, new strategies and policies should start from the national level, involving stakeholders, including citizens, civil society groups, the news media and corporations. These updates may entail a significant expenditure of resources but will create stronger national level policies in accordance with the ethics, values, paradigms and sustainable development goals of the United Nations. As Frieden et al. [93] state, "National policies, especially of large countries, affect the international economy in important ways" (p. 27). One example is the initial step taken by the German government, which has just released a strategy paper on the cornerstones the federal government, where they identified a need to support a strategy for AI. It states "Usable, high-quality data must be significantly increased without violating personal rights, the right to informational self-determination or other fundamental rights. Data from the public sector and science are increasingly being opened up for AI research, enabling their economic and public benefit use in the sense of an open-data strategy." [94] (p. 1). The paper lists 13 goals, starting with establishing an "Artificial Intelligence made in Germany" seal of quality and ending with the commitment to adhere to the recommendations of the Commission on Data Ethics [94] (p. 2). However, policies on the fulfillment of these strategies have yet to be created. Similarly, all European Union (EU) members have signed a Declaration of Cooperation on AI to put forward the European approach to Artificial Intelligence based on three pillars [95]. These pillars are: being at the forefront of technological developments and encouraging their uptake by the public and private sectors; preparing for socio-economic changes brought about by AI; and ensuring an appropriate ethical and legal framework. Formation of these pillars is the crucial initial step toward the implementation of AI by EU nations. As Papadopoulos et al. [41] point out, exploring and decoding the relevant contagion mechanisms is a major way to prevent the spread of economic crisis. Therefore, in the future, to reduce the global impact of AI, there should be deceleration of cooperation between nations at the global level to prepare shared standards of practice for the global socio-economic shift as it occurs in both production and service outsourcing, without competitive advantage in mind.

Likewise, as stated by the related work referred to in the background section and in our sustainability analysis, ethics is a major consideration when making sure AI contributes to what we want, all without imposing serious humanistic, social, and legal concerns. To do this, guidance from a proper code of ethics is needed. However, developing such a 'proper' one is a significant challenge. For example, the current version of the ACM Code of Ethics and Professional Practice created a debate, specifically about principle 1.2, Avoid Harm, which now reads, "In this document, 'harm' means negative consequences, especially when those consequences are significant and unjust. Examples of harm include unjustified physical or mental injury, unjustified destruction or disclosure of information, and unjustified damage to property, reputation, and the environment." and then proceeds to request ethical justifications for exceptions. The question is when is harm "ethically justified" and who takes that decision on which basis if the Code of Ethics does not provide guidance on that. 
However, the guidance of "to minimize the possibility of indirectly or unintentionally harming others, computing professionals should follow generally accepted best practices unless there is a compelling ethical reason to do otherwise" gives little concrete advice, instead circling back to already accepted practices and a call to think ethically. Other professional associations have produced similar efforts, but they too have had similar struggles in phrasing effective guidance; for example, the German Society for Informatics (Gesellschaft für Informatik) put out a principle for social responsibility, holding the engineer accountable for the social and societal impacts of his or her technological work, but the organization did not mention harm of any kind [96].

To take this further, the Future of Computing Academy (FCA), which is part of the ACM, calls for researchers to consider the negative societal consequences of their work and to make this a part of their peer-reviewed publications [97]. Specifically, for AI, it seems that it may then carry the values of the human that coded it, either by how an algorithm is designed (the choices that are prescribed, e.g., if $\mathrm{x}$ equals $\mathrm{z}$ then do $\mathrm{y}$ ) or the training data that is supplied to a neural network, which also has choices encoded. Consequently, further research is required along the lines of values in software engineering. We conclude that teaching students about their responsibility for the long-term potential impact of their work and applying their code of ethics is crucial.

To sum up, one can see that value, collaboration, sharing responsibilities, ethics are important measures that should be taken in to consideration by all stakeholders to reduce the negative impact of AI towards sustainability. If these measures are taken in to consideration, there is possibilities that, "No matter how clever or artificially intelligent computers get, and no matter how much they help us advance, they will always be strictly machines and we will be strictly humans" [98] (p. 59).

\section{Conclusions}

In this paper, we reviewed the potential long-term impacts of AI on sustainability and, more specifically, on sustainable development by performing a sustainability analysis [14,29]. We explored the impacts of AI by using the five analysis categories-individual, social, economic, technical, and environmental-reviewing the current scientific literature on $\mathrm{AI}$ in each of the fields, and iterating the analysis with a focus group of experts.

Our main findings on how AI may impact sustainable development are as follows: On an economic level, AI is already a major industry and can displace low-skilled workers. On the technical level, with the advancement, AI may learn and teach how to code itself causing disruption towards jobs in the Information Technology (IT) industry. On an environmental level, AI can impact waste and pollution management and can also negatively impact sustainability in the form of power and resource consumption. On the individual level, AI may impact work, empower users with agents, and affect interactions or social isolation. Finally, on the social level, AI can take a minor role in assisting in communities, managing social media, automating routine tasks that are commonly outsourced, and participating in digital storytelling. It seems almost peculiar that a main outcome of our sustainability analysis is that $\mathrm{AI}$ can have positive and negative impacts on all five dimensions, and then again that makes sense, because it is a means, not an end. AI is a tool and as such it can be used for good or bad, and it is up to the developers as well as all stakeholders involved to take sound ethical decisions based on values commonly shared amongst citizens for the joint vision of a sustainable and resilient future.

The key findings of the present study are beneficial for all stakeholders, such as citizens, researchers, companies, application developers, and governmental organizations that have both a direct and indirect influence on the implementation, adoption, and regulation of AI. The presented sustainability analysis diagram can be used as a tool to understand both the positive and negative impact of ANI, ASI, and AGI on the five dimensions of sustainability. For future work, we envision several more detailed studies:

(i) AI Application Domains: A more in-depth sustainability analysis should be performed for several application domains of AI whereby an analysis of the three orders of effect (life cycle, enabling, and structural) is included. 
(ii) Ethics and transparency of AI: An interdisciplinary analysis that considers the transparency and ethical aspects of AI should be performed in a joint effort by behavioral psychologists, philosophers of science, psychologists, and computer scientists.

(iii) Responsibility \& accountability for AI: A qualitative analysis should be conducted on how much citizens are willing to give up the freedom of choice and have AI take somewhat optimized decisions for them, how much operators are willing to pass on their responsibility to AI, and how much developers are willing to be accountable in case something fails, along with how to allow for and ensure transparency; and

(iv) Perceptions of AI: A larger-scale empirical analysis should be carried out on individuals' perceptions in diverse stakeholder roles toward having AI integrated in society on several levels of technological intervention, e.g., as small-scale personal assistants, as substitute teachers, nurses, and doctors, or as decision support systems for governments and legislation.

Author Contributions: Conceptualization, J.K., B.P.; Methodology, B.P., J.K., J.P.; Resources, B.P., A.K., J.P. and W.Z.; Writing—Original Draft Preparation, J.K., B.P.; Writing—Review \& Editing, J.K., B.P., A.K., J.P.; Visualization, B.P. Both J.K. and B.P. have made equal contributions towards the paper.

Funding: This research received no external funding.

Conflicts of Interest: The authors declare no conflicts of interests.

\section{References}

1. McClure, P.K. "You're Fired," Says the Robot. Soc. Sci. Comput. Rev. 2017. [CrossRef]

2. McCarthy, J.; Minsky, M.L.; Rochester, N.; Shannon, C.E. A proposal for the Dartmouth summer research project on artificial intelligence. AI Mag. 2006, 27, 12-14. [CrossRef]

3. Copeland, B.J. The Essential Turing: Seminal Writings in Computing, Logic, Philosophy, Artificial Intelligence, and Artificial Life: Plus The Secrets of Enigma; Copeland, B.J., Ed.; Oxford University Press: Oxford, UK, 2004; ISBN 0-19-825080-0.

4. Tegmark, M. Life 3.0: Being Human in the Age of Artificial Intelligence; Knopf: New York, NY, USA, 2017.

5. Harari, Y. The Guardian. 2017. Available online: https://www.theguardian.com/culture/yuval-noah-harari (accessed on 3 November 2018).

6. Morgan, C. Researchers Say Fake News Had "Substantial Impact" on 2016 Election. Available online: http:/ / thehill.com/policy/cybersecurity/381449-researchers-say-fake-news-had-substantial-impacton-2016-election (accessed on 6 July 2018).

7. Pamela, B. Rutledge How Cambridge Analytica Mined Data for Voter Influence. Available online: https:/ / www.psychologytoday.com/us/blog/positively-media/201803/how-cambridge-analyticamined-data-voter-influence (accessed on 20 June 2018).

8. Booch, G. Don't Fear Superintelligent ai. TED@IBM. Available online: https://www.ted.com/talks/grady_ booch_don_t_fear_superintelligence?language=en (accessed on 1 July 2018).

9. Kevin, K. How AI Can Bring on a Second Industrial Revolution. TED Talk. Available online: https: //www.ted.com/talks/kevin_kelly_how_ai_can_bring_on_a_second_industrial_revolution (accessed on 10 May 2018).

10. Harris Sam Can We Build Ai Without Losing Control Over It? Available online: https://www.ted.com/ talks/sam_harris_can_we_build_ai_without_losing_control_over_it (accessed on 15 June 2018).

11. Tufekci, Z. Machine Intelligence Makes Human Morals More Important. TED Talk, 2016. Available online: https://www.ted.com/talks/zeynep_tufekci_machine_intelligence_makes_human_morals_more_ important (accessed on 19 June 2018).

12. Tegman, M. How to Get Empowered, Not Overpowered, by ai. TED Talk, 2018. Available online: https:/ /www. ted.com/talks/max_tegmark_how_to_get_empowered_not_overpowered_by_ai?language=en (accessed on 11 July 2018).

13. Fisher, D.H. A Selected Summary of AI for Computational Sustainability. In Proceedings of the Thirty-First AAAI Conference on Artificial Intelligence, San Francisco, CA, USA, 4-9 February 2017; pp. 4852-4857. 
14. Becker, C.; Betz, S.; Chitchyan, R.; Duboc, L.; Easterbrook, S.M.; Penzenstadler, B.; Seyff, N.; Venters, C.C. Requirements: The Key to Sustainability. IEEE Softw. 2016, 33, 56-65. [CrossRef]

15. Tredinnick, L. Artificial intelligence and professional roles. Bus. Inf. Rev. 2017, 34, 37-41. [CrossRef]

16. Hoehndorf, R.; Queralt-Rosinach, N. Data Science and symbolic AI: Synergies, challenges and opportunities. Data Sci. 2017, 1, 27-38. [CrossRef]

17. Jiang, F.; Jiang, Y.; Zhi, H.; Dong, Y.; Li, H.; Ma, S.; Wang, Y.; Dong, Q.; Shen, H.; Wang, Y. Artificial intelligence in healthcare: Past, present and future. Stroke Vasc Neurol. 2017, 2, 230-243. [CrossRef] [PubMed]

18. Huang, M.-H.; Rust, R.T. Artificial Intelligence in Service. J. Serv. Res. 2018, 21, 155-172. [CrossRef]

19. Weizenbaum, J. ELIZA-A Computer Program For the Study of Natural Language Communication Between Man And Machine. Commun. ACM 1966, 9, 36-45. [CrossRef]

20. Müller, V.C. Risks of general artificial intelligence. J. Exp. Theor. Artif. Intell. 2014, 26, 297-301. [CrossRef]

21. Strelkova, O.; Pasichnyk, O. Three Types of Artificial Intelligence; Khmelnitsky National University: Khmelnytskyi, Ukraine, 2017; pp. 1-4.

22. Wang, P.; Goertzel, B. Introduction: Aspects of artificial general intelligence. In Proceedings of the 2007 Conference on Advances in Artificial General Intelligence: Concepts, Architectures and Algorithms: Proceedings of the AGI Workshop 2006; IOS Press: Amsterdam, The Netherlands, 2007; pp. 1-16.

23. Cully, A.; Clune, J.; Tarapore, D.; Mouret, J.B. Robots that can adapt like animals. Nature 2015, 521, $503-507$. [CrossRef] [PubMed]

24. Silver, D.; Huang, A.; Maddison, C.J.; Guez, A.; Sifre, L.; Van Den Driessche, G.; Schrittwieser, J.; Antonoglou, I.; Panneershelvam, V.; Lanctot, M.; et al. Mastering the game of Go with deep neural networks and tree search. Nature 2016, 539, 484-489. [CrossRef] [PubMed]

25. Shead, S. Stephen Hawking And Elon Musk Backed 23 Principles To Ensure Humanity Benefits From AI. Available online: https:/ / nordic.businessinsider.com/stephen-hawking-elon-musk-backed-asimolar-aiprinciples-for-artificial-intelligence-2017-2 (accessed on 29 July 2018).

26. Carriço, G. The EU and artificial intelligence: A human-centred perspective. Eur. View 2018, 17, 29-36. [CrossRef]

27. Popenici, S.A.D.; Kerr, S. Exploring the impact of artificial intelligence on teaching and learning in higher education. Res. Pract. Technol. Enhanc. Learn. 2017, 12, 22. [CrossRef]

28. Pavaloiu, A.; Kose, U. Ethical Artificial Intelligence-An Open Question. J. Multidiscip. Dev. 2017, 2, $15-27$.

29. Penzenstadler, B. Sustainability analysis and ease of learning in artifact-based requirements engineering: The newest member of the family of studies (It's a girl!). Inf. Softw. Technol. 2018, 95, 130-146. [CrossRef]

30. Hilty, L.M.; Aebischer, B. Ict for sustainability: An emerging research field. Adv. Intell. Syst. Comput. 2015. [CrossRef]

31. Penzenstadler, B.; Femmer, H.; Richardson, D. Who is the advocate? Stakeholders for sustainability. In Proceedings of the 2013 2nd International Workshop on Green and Sustainable Software (GREENS), San Francisco, CA, USA, 20 May 2013.

32. Seyff, N.; Betz, S.; Duboc, L.; Venters, C.; Becker, C.; Chitchyan, R.; Penzenstadler, B.; Nobauer, M. Tailoring Requirements Negotiation to Sustainability. In Proceedings of the 2018 IEEE 26th International Requirements Engineering Conference (RE), Banff, AB, Canada, 20-24 August 2018; Volume 9, pp. 304-314.

33. Brundtland, G.H. Our Common Future: Report of the World Commission on Environment and Development. United Nations Commun. 1987, 4, 300. [CrossRef]

34. United Nations. The Millennium Development Goals Report 2009; United Nations: New York, NY, USA, 2009.

35. United Nations. The Millennium Development Goals Report 2015; United Nations: New York, NY, USA, 2015.

36. Department of Public Information, United Nations. Sustainable Development Goals 2015-2030; United Nations Publications: New York, NY, USA, 2015.

37. United Nations. The Sustainable Development Goals Report 2018; United Nations: New York, NY, USA, 2018.

38. Andrews, W. Craft an Artificial Intelligence Strategy: A Gartner Trend Insight Report What You Need to Know; Gartner, Inc.: Stamford, CT, USA, 2018.

39. Greg, C.; Hancock, M. Tech Sector Backs British Ai Industry With Multi Million Pound Investment. Available online: https://www.gov.uk/government/news/tech-sector-backs-british-ai-industry-with-multi-millionpound-investment--2 (accessed on 25 July 2018).

40. Cerulus Laurens Macron: France to Invest Nearly €1.5B for AI Until 2022. Available online: https: / /www. politico.eu/article/macron-france-to-invest-nearly-e1-5-billion-for-ai-until-2022/ (accessed on 7 May 2018). 
41. Papadopoulos, I.; Trigkas, M.; Karagouni, G.; Papadopoulou, A. The contagious effects of the economic crisis regarding wood and furniture sectors in Greece and Cyprus. World Rev. Entrep. Manag. Sustain. Dev. 2014, 10, 334. [CrossRef]

42. Hawking, S. Stephen Hawking: AI Will Be "Either Best or Worst Thing" for Humanity. Available online: https:/ / www.theguardian.com/commentisfree/2016/dec/01/stephen-hawking-dangerous-timeplanet-inequality (accessed on 15 June 2018).

43. Lee, C.C.; Czaja, S.J.; Sharit, J. Training older workers for technology-based employment. Educ. Gerontol. 2009, 35, 15-31. [CrossRef] [PubMed]

44. Organisation for Economic Co-operation and Development. Maintaining Prosperity in An Ageing Society: The OECD Study on the Policy Implications of Ageing Workforce Aging: Consequences and Policy Responses; Organisation for Economic Co-operation and Development: Paris, France, 1998.

45. LeCun, Y.; Bengio, Y.; Hinton, G.E. Deep learning. Nature 2015, 521, 436-444. [CrossRef] [PubMed]

46. Simard, P.Y.; Steinkraus, D.; Platt, J.C. Best practices for convolutional neural networks applied to visual document analysis. In Proceedings of the Seventh International Conference on Document Analysis and Recognition 2003, Edinburgh, UK, 6 August 2003; Volume 1, pp. 958-963.

47. Duan, Y.; Schulman, J.; Chen, X.; Bartlett, P.L.; Sutskever, I.; Abbeel, P. RL ${ }^{2}$ : Fast Reinforcement Learning via Slow Reinforcement Learning. arXiv, 2016; arXiv:1611.02779.

48. Simonite, T. AI Software Learns to Make AI Software. Available online: https://www.technologyreview. com/s/603381/ai-software-learns-to-make-ai-software/ (accessed on 10 July 2018).

49. Anderson, R.E.; Johnson, D.G.; Gotterbarn, D.; Perrolle, J. Using the new ACM code of ethics in decision making. Commun. ACM 1993, 36, 98-107. [CrossRef]

50. Al-Jarrah, O.; Abu-Qdais, H. Municipal solid waste landfill siting using intelligent system. Waste Manag. 2006. [CrossRef] [PubMed]

51. Ramchandran, G.; Nagawkar, J.; Ramaswamy, K.; Ghosh, S.; Goenka, A.; Verma, A. Assessing environmental impacts of aviation on connected cities using environmental vulnerability studies and fluid dynamics: an Indian case study. AI Soc. 2017. [CrossRef]

52. Norouzzadeh, M.S.; Nguyen, A.; Kosmala, M.; Swanson, A.; Palmer, M.S.; Packer, C.; Clune, J. Automatically identifying, counting, and describing wild animals in camera-trap images with deep learning. Proc. Natl. Acad. Sci. USA 2018, 115, E5716-E5725. [CrossRef] [PubMed]

53. Igliński, H.; Babiak, M. Analysis of the Potential of Autonomous Vehicles in Reducing the Emissions of Greenhouse Gases in Road Transport. Procedia Eng. 2017, 192, 353-358. [CrossRef]

54. Packard, V. The Waste Makers; David McKay Co., Inc.: New York, NY, USA, 1960.

55. Victor, S.P.; Kumar, S.S. Planned Obsolescence-Roadway To Increasing E-Waste in Indian Government Sector. Int. J. Soft Comput. Eng. 2012, 2, 554-559.

56. Guiltinan, J. Creative destruction and destructive creations: Environmental ethics and planned obsolescence. J. Bus. Ethics 2009. [CrossRef]

57. World Business Council for Sustainable Development (WBCSD). Eco-Efficiency: Creating more Value with less Impact; WBCSD: Geneva, Switzerland, 2000.

58. Yamin, A.E. The right to health under international law and its relevance to the United States. Am. J. Public Health 2005, 95, 1156-1161. [CrossRef] [PubMed]

59. Hanley, N.; Shogren, J.F.; White, B. The Economy and the Environment: Two Parts of a Whole. In Environmental Economics in Theory and Practice; Macmillan Education: London, UK, 1997; pp. 1-21.

60. Lightman, A. In Praise of Wasting Time (TED Books); Simon and Schuster: New York, NY, USA, 2018.

61. Schor, J.B. The Overworked American: The Unexpected Decline of Leisure. Contemp. Sociol. 1992, $21,843$. [CrossRef]

62. Song, J.-T.; Lee, G.; Kwon, J.; Park, J.-W.; Choi, H.; Lim, S. The Association between Long Working Hours and Self-Rated Health. Ann. Occup. Environ. Med. 2014, 26, 2. [CrossRef] [PubMed]

63. Bannai, A.; Tamakoshi, A. The association between long working hours and health: A systematic review of epidemiological evidence. Scand. J. Work. Environ. Health 2014, 40, 5-18. [CrossRef] [PubMed]

64. Alexandris, K.; Carroll, B. Constraints on recreational sport participation in adults in Greece: Implications for providing and managing sport services. J. Sport Manag. 1999, 13, 317-332. [CrossRef]

65. Khakurel, J.; Melkas, H.; Porras, J. Tapping into the wearable device revolution in the work environment: A systematic review. Inf. Technol. People 2018, 31, 791-818. [CrossRef] 
66. Chowdhury, A.P. 10 Areas Where Artificial Intelligence Is Going To Impact Our Lives In Future. Available online: https:/ / analyticsindiamag.com/10-areas-artificial-intelligence-going-impact-lives-future/ (accessed on 25 June 2018).

67. Sorell, T.; Draper, H. Robot carers, ethics, and older people. Ethics Inf. Technol. 2014, 16, 183-195. [CrossRef]

68. Chen, T.L.; Bhattacharjee, T.; Beer, J.M.; Ting, L.H.; Hackney, M.E.; Rogers, W.A.; Kemp, C.C. Older adults' acceptance of a robot for partner dance-based exercise. PLOS ONE 2017, 12. [CrossRef] [PubMed]

69. Ivanov, S. Robonomics_Principles, Benefits, Challenges, Solutions; Yearbook of Varna University of Management: Varna, Bulgaria, 2017; Volume 10.

70. Gale, C.R.; Westbury, L.; Cooper, C. Social isolation and loneliness as risk factors for the progression of frailty: The English Longitudinal Study of Ageing. Age Ageing 2017. [CrossRef] [PubMed]

71. Villani, C. For a Meaningful Artificial Intelligence: Towards a French and European Strategy; Government of France: Paris, France. Available online: https:/ / www.aiforhumanity.fr/pdfs/MissionVillani_Report_ENG-VF.pdf (accessed on 3 November 2018).

72. Bostrom, N.; Yudkowsky, E. The ethics of artificial intelligence. In The Cambridge Handbook of Artificial Intelligence; Cambridge University Press: Cambridge, UK, 2011; pp. 316-334.

73. Dignum, V. Ethics in artificial intelligence: introduction to the special issue. Ethics Inf. Technol. 2018, 20, 1-3. [CrossRef]

74. Simpson, J.A.; Farrell, A.K.; Oriña, M.M.; Rothman, A.J. Power and social influence in relationships. In APA Handbook of Personality and Social Psychology, Volume 3: Interpersonal Relations; American Psychological Association: Washington, DC, USA, 2015; Volume 3, pp. 393-420.

75. Wisskirchen, G.; Thibault, B.; Bormann, B.U.; Muntz, A.; Niehaus, G.; Soler, G.J.; Von Brauchitsch, B. Artificial Intelligence and Robotics and Their Impact on the Workplace; IBA Global Employment Institute: London, UK, 2017.

76. Hasse, C. Posthuman learning: AI from novice to expert? AI Soc. 2018. [CrossRef]

77. Serholt, S.; Barendregt, W.; Vasalou, A.; Alves-Oliveira, P.; Jones, A.; Petisca, S.; Paiva, A. The case of classroom robots: Teachers' deliberations on the ethical tensions. AI Soc. 2017. [CrossRef]

78. Borenstein, J.; Arkin, R.C. Nudging for good: Robots and the ethical appropriateness of nurturing empathy and charitable behavior. AI Soc. 2017. [CrossRef]

79. Fan, W.; Gordon, M.D. The power of social media analytics. Commun. ACM 2014. [CrossRef]

80. Varol, O.; Ferrara, E.; Menczer, F.; Flammini, A. Early detection of promoted campaigns on social media. EPJ Data Sci. 2017. [CrossRef]

81. Copeland, S.; de Moor, A. Community Digital Storytelling for Collective Intelligence: Towards a Storytelling Cycle of Trust. AI Soc. 2018, 33, 101-111. [CrossRef]

82. Kingston, J. Artificial Intelligence and Legal Liability. arXiv 2018; arXiv:1802.07782.

83. Hallevy, P.G. The Criminal Liability of Artificial Intelligence Entities. SSRN Electron. J. 2010. [CrossRef]

84. Yano, K. How Artificial Intelligence Will Change HR. People Strategy, p. 42+. Academic OneFile, 2017. Available online: http:/ / go.galegroup.com/ps/anonymous?id=GALE \T1 \textbar\{\}A499598708\&sid=googleScholar\& $\mathrm{v}=2.1$ \&it $=\mathrm{r} \&$ linkaccess $=$ abs\&issn $=19464606 \& \mathrm{p}=\mathrm{AONE \& sw}=\mathrm{w}$ (accessed on 3 November 2018).

85. Kirkpatrick, K. AI in contact centers. Commun. ACM 2017. [CrossRef]

86. Lebeuf, C.; Storey, M.-A.; Zagalsky, A. Software Bots. IEEE Softw. 2018, 35, 18-23. [CrossRef]

87. Ehrenfeld, J. Beyond sustainability: Why an all-consuming campaign to reduce unsustainability fails. ChangeThis 2006, 25, 1-17.

88. Rescher, N. Introduction to Value Theory (Upa Nicholas Rescher Series), 1st ed.; Prentice Hall: Englewood Cliffs, NJ, USA, 1969.

89. Rokeach, M. The Nature of Human Values; Free Press: New York, NY, USA, 1973; ISBN 0029267501.

90. Cheng, A.-S.; Fleischmann, K.R. Developing a meta-inventory of human values. Proc. Am. Soc. Inf. Sci. Technol. 2010, 47, 1-10. [CrossRef]

91. Leiserowitz, A.A.; Kates, R.W.; Parris, T.M. Sustainability Values, Attitudes, and Behaviors: A Review of Multinational and Global Trends. Annu. Rev. Environ. Resour. 2006, 31, 413-444. [CrossRef]

92. Lammers, J.; Stoker, J.I.; Rink, F.; Galinsky, A.D. To Have Control Over or to Be Free From Others? The Desire for Power Reflects a Need for Autonomy. Personal. Soc. Psychol. Bull. 2016, 42, 498-512. [CrossRef] [PubMed]

93. Frieden, J.; Rogowski, R. The Impact of the International Economy on National Policies: An Analytical Overview; Cambridge University Press: Cambridge, UK, 1996. 
94. Bundesregierung, D. Eckpunkte der Bundesregierung für Eine Strategie Künstliche Intelligenz; Bonn. Available online: https:/ / www.bmbf.de/files/180718\%20Eckpunkte_KI-Strategie\%20final\%20Layout.pdf (accessed on 27 July 2018).

95. Digital Single Market EU Member States Sign up to Cooperate on Artificial Intelligence. Available online: https://ec.europa.eu/digital-single-market/en/news/eu-member-states-sign-cooperate-artificialintelligence (accessed on 28 July 2018).

96. Gesellschaft für Informatik Ethische Leitlinien. Available online: https:/ / gi.de/ueber-uns/organisation/ unsere-ethischen-leitlinien/ (accessed on 1 August 2018).

97. Gibney, E. The ethics of computer science: This researcher has a controversial proposal. Nature 2018. [CrossRef]

98. Roberts, K. The impact of leisure on society. World Leis. J. 2000, 42, 3-10. [CrossRef]

2018 by the authors. Licensee MDPI, Basel, Switzerland. This article is an open access article distributed under the terms and conditions of the Creative Commons Attribution (CC BY) license (http://creativecommons.org/licenses/by/4.0/). 